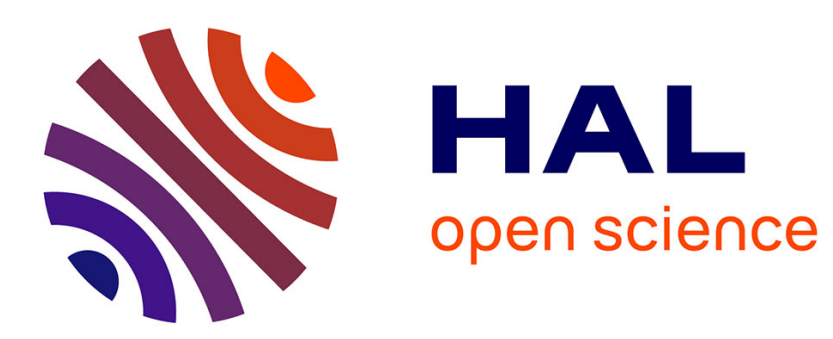

\title{
In-transit cold treatment: a case of institutional path dependence
}

Jean Marie Codron, Pasquale Lubello

\section{To cite this version:}

Jean Marie Codron, Pasquale Lubello. In-transit cold treatment: a case of institutional path dependence. Journal of Institutional Economics, 2020, 16 (4), pp.463-479. 10.1017/S1744137420000041. hal-02624856

\section{HAL Id: hal-02624856 \\ https://hal.inrae.fr/hal-02624856}

Submitted on 26 May 2020

HAL is a multi-disciplinary open access archive for the deposit and dissemination of scientific research documents, whether they are published or not. The documents may come from teaching and research institutions in France or abroad, or from public or private research centers.
L'archive ouverte pluridisciplinaire HAL, est destinée au dépôt et à la diffusion de documents scientifiques de niveau recherche, publiés ou non, émanant des établissements d'enseignement et de recherche français ou étrangers, des laboratoires publics ou privés. 


\title{
In-transit cold treatment: a case of institutional path dependence
}

\author{
Pasquale Lubello, UMR MOISA, Montpellier Supagro, INRA - CIRAD, CIHEAM - IAMM, \\ Université de Montpellier, Montpellier, FRANCE, lubello@supagro.fr
}

Jean-Marie Codron, UMR MOISA, INRA - CIRAD, Montpellier Supagro, CIHEAM IAMM, Université de Montpellier, Montpellier, FRANCE, cordon@inra.supagro.fr

\begin{abstract}
$\underline{\text { Abstract }}$
In-transit cold treatment consists of exposing food commodities - generally fresh agricultural products - to temperatures approaching $0 \mathrm{C}^{\mathbf{o}}$ for a variable number of days during shipping in purpose-equipped containers in order to manage the risks of quarantine contamination. In this paper, we show that in-transit cold treatment is frequently required in the international trade of apples potentially affected by Mediterranean fruit fly (Ceratitis Capitata), despite the existence of potentially less costly and equally effective alternative means of applying the same treatment, in particular 'cold storage'. We then try to understand why these alternative methods do not emerge spontaneously or become more widespread. We suggest that technical aspects and their respective costs are not always the most important factors. Transaction costs may also come into play. In accordance with 'institutional path dependence' literature, we suggest that the negotiation costs a country has to bear in order to encourage its trading partners to adopt an alternative treatment are high enough for it to be preferable to continue using the current solution, despite its higher adoption cost.
\end{abstract}

Keywords: apples, international trade, in-transit cold treatment, institutions, path dependence

Lubello, P. ; Codron, J.M. (2020). In-transit cold treatment: a case of institutional path dependence. Journal of Institutional Economics, 1-17

https://doi.org/10.1017/S1744137420000041 


\section{Introduction}

In accordance with the Sanitary and Phytosanitary (SPS) Agreement (1995), each country has the right to take the SPS measures necessary to ensure the protection of plant, animal and human life or health from biological or chemical contamination induced by trade, provided that such measures do not constitute a means of arbitrary discrimination between trade partners or a disguised restriction on international trade. In the specific case of the trade of fresh produce, for example, members can specify the number of chemical molecules allowed within their territory, the maximum residue limits (MRLs) tolerated, the quarantine organisms (QOs) from which they wish to protect themselves and the technical measures with which trading partners must comply to ensure the safety of the goods shipped.

As the number of these regulations has constantly increased since the mid-1990s ${ }^{1}$ and adoption $\operatorname{costs}^{2}$ can be significant for exporters, the majority of economic research on this topic has tried to evaluate the impact of SPS measures on trade flows (Beghin and Bureau 2002; Marette and Beghin 2010; Swinnen and Vandemoortele 2011). While this particular question has understandably attracted the attention of many international trade economists, we suggest that the authors in question have often forgotten or neglected to analyze the economic dimensions of the explanatory variable itself (the regulatory measures), perhaps because of the implicit assumption that a standard is ultimately nothing more than a series of words stipulating conditions, thereby making them easy to modify when necessary such that they are the best standards that an economic agent can rationally expect (Alchian 1950; Alchian and Demsetz 1973; North and Thomas 1973).

We do not agree with this definition of a standard. Echoing North (1990), we know that producing or modifying a standard involves high fixed costs as well as transaction costs. Such costs are significant and, together with the learning effects and coordination effects, provide powerful incentives for institutional stability while often making change impossible (Donnelly 2009). Consequently, there is no guarantee that the standard applied is the best available norm. Ultimately, trade flows are more dependent on the efficiency of the market that produces standards than on any one particular standard.

When we apply such reasoning to SPS measures, other empirical and theoretical issues become relevant such as the cost of negotiating an SPS measure, whether or not negotiating or renegotiating ${ }^{3}$ an SPS measure entails transaction costs and the level of market efficiency in such conditions. In the following pages, we endeavor to show that negotiating or renegotiating an SPS bilateral protocol is not without cost. Negotiation or renegotiation costs may sometimes be so high that it is ultimately preferable for an exporting country to continue using the existing

\footnotetext{
1198 SPS notifications submitted during 1995 compared to 1,632 during the course of 2018. Source: WTOSPSIMS dataset. As with SPS measures, the number of technical barriers to trade (TBT) has also increased since the 1990s. In this paper, however, we chose to focus exclusively on SPS aspects linked to the trade of fresh produce.

${ }^{2}$ Adoption costs can be defined as the operating costs that an exporter has to bear in order to comply with the phytosanitary constraints imposed by the national SPS authority of the importing country. Added to conventional production costs, these operating costs reduce the tradable volumes of an exporter compared to those that could have been traded in the absence of a quarantine threat and, therefore, of phytosanitary treatment. Experts assessing the impact of SPS measures on trade flows usually assume the existing of such operating costs.

${ }^{3}$ Negotiation costs are the costs that an exporting country has to bear to set standards by mutual agreement with its trading partners (bilateral protocol). Similarly, renegotiation costs are the costs that an exporting country has to bear to make its trading partners agree to alter previous measures in favor of alternative ones (potentially more efficient).
} 
standard, despite its higher adoption costs ('maladaptation cost': Williamson 1985, 1993), rather than try to modify it. The institutional economic literature on 'path dependence' (North 1990; David 1994) includes numerous factual examples demonstrating the impact of past regulatory choices on the present (Hansen and Hansen 2007; Poelmans and Taylor 2019). This helps us to analyze these types of situation.

The aim of this paper is to draw on this path-dependence literature in order to shed light on a specific pest risk management standard: the 'USDA in-transit cold treatment protocol' .

Like other national in-transit cold treatment protocols, the north-American protocol specifies all the technical conditions that an exporting country must comply with to introduce a given type of fresh produce (deciduous, stone and citrus fruits, etc.) onto US soil. These conditions include the nature of the targeted quarantine pest, temperature/days pairings, the number and position of thermal sensors (atmospheric or within the pulp of the fruit), the type of container and specific equipment required.

As we will point out in the following pages, the 'USDA in-transit cold treatment protocol' is by far the most commonly adopted bilateral protocol in international trade, despite the absence of any international legal obligation for other countries to adopt it. Potentially less costly and equally effective alternatives to 'in-transit cold treatment', such as 'cold-storage before shipping' exist, but are not widely adopted.

In order to understand the predominance of the USDA protocol in the international trade of fresh produce as well as the reasons for which alternative means of providing the same level of efficiency do not emerge spontaneously or are not more widespread, we focus on the specific case of French apple exports. This particular case study is of interest in many respects.

First, apples rank just after bananas (FAOstat) in global trading volumes. Second, apple exporting countries are often contaminated by the Mediterranean fruit fly (MFF) and therefore do not comply with legislation in MFF-free importing countries in South Asia and the Americas, where demand for apples has witnessed rapid growth. This is the case in France, which ranks among the seven main apple exporting countries in the world. Third, as MFF are sensitive to cold temperatures, the use of cold treatment is usually recommended or imposed through bilateral protocols in order to eradicate MFF when these are deemed to be quarantine pests in the importing country. Fourth, apples are a rare example of fresh fruit that can be kept in cold storage for a long time - up to one year in ultra-low-oxygen cold rooms - without any significant impact on their organoleptic properties. As we will see below, this characteristic (of natural resistance to cold temperatures) provides exporting countries with the possibility of designing a pest risk management system which differs from the 'cold treatment in transit', such as conventional cold storage before leaving the exporting country. Finally, conventional cold storage has been adopted by certain countries such as China when importing from France, thus proving the existence of an efficient alternative to the USDA in-transit cold treatment protocol. As we will see in sections 2 and 3, while the cold treatment protocol imposed on French exporters by importing countries is more often than not the USDA protocol, the existence of an alternative contributes to making institutional path dependence analysis relevant.

In the first part of this paper, we will describe the theoretical framework which serves as a background to our work. As stated above, we will use the contributions of neo-institutionalist economists (Coase 1937, North 1990; Williamson 1985), and in particular contributions

\footnotetext{
4 Technically called "USDA-APHIS T107a". Document available at: https://www.aphis.usda.gov/aphis/ourfocus/planthealth/complete-list-of-electronic-manuals.
} 
relating to path dependence (Arthur 1984; David 1985; North 1990) and international trade (Dür et al. 2013; Lavallée 2016; Rodrik et al. 2004; Vidigal 2017). In the second part, we will retrace the history of the emergence of cold treatment, and more particularly in-transit cold treatment, as a pest risk management standard. We will show that, in the absence of an international standard in this field, the US public norm has become a reference in world trade. We will then use the case study of French apple exports to describe the proposed alternative practice, its potential strengths and the associated constraints, particularly those which are institutional in nature preventing its dissemination at the international level. We will then present our conclusion.

\section{1) Theoretical framework}

\subsection{General elements on institutional path dependence}

In 1985, P. David (1985) published a paper on the history and economics of the QWERTY standard, the most widely used keyboard layout. In this article, which would strongly influence subsequent literature in the field of evolutionary economics addressing technological innovation, David explained how a given technology - the QWERTY keyboard layout - was able to emerge in the world of mechanical typewriters and persist until today's electronic computer keyboards, despite the proven existence of more ergonomic alternatives ${ }^{5}$ (DVORAK keyboard layout) requiring no additional production costs. In arguing his point, David drew inspiration from W.B. Arthur's theoretical work on increasing adoption returns in the complex technologies sector (Arthur 1984, 1989, 1990).

Arthur pointed out how positive feedback economics (PFE) significantly differs from conventional economics (CE) in the selection process of technologies. First, PFE is based on the assumption that adoption results from increasing returns while in $\mathrm{CE}$, it results from diminishing returns, leading to the best solution being retained once the less efficient alternatives have been discarded. Second, PFE fits well with modern, complex, knowledgeintensive technologies that 'often display increasing returns to adoption in that the more they are adopted, the more experience is gained with them, and the more they are improved'. This is not the case of $\mathrm{CE}$, which mostly deals with 'standard' technologies. Third, the positive feedback process generated by former technologies creates a 'lock-in situation' where neither the predictability nor the allocative efficiency of the market outcome can be guaranteed, while the diminishing returns of $\mathrm{CE}$ always ensure the predictability of the final equilibrium. Finally, the PFE selection process is not as deterministic as that of $\mathrm{CE}$, as it often results from insignificant variables - 'historical small events' - lending an initial advantage to the adoption of a particular technology, although it is not necessarily the most efficient in the long run.

Adopted by authors from different backgrounds (Krugman 1994; Pierson 2000; Pomeranz and Topik $1999^{6}$ ), these ideas also attracted the attention of neo-institutionalist economists such as O. Williamson (1993), who worked on the concept of 'path dependence remediability', or D. North (1990), who transposed the concepts of 'path dependence' and 'lock-in situation' to the institutional field.

\footnotetext{
${ }^{5}$ It should be recalled, however, that there is controversy concerning the superiority of the Dvorak keyboard and therefore the results obtained by David (Liebowitz and Margolis 1990, 1995)

${ }^{6}$ For a broader overview of Arthur's theses in the fields of economics, management, politics and social sciences, see Donnelly's article (Donnelly 2009).
} 
To use North's terminology (1990), institutions are the rules of the game commonly accepted by the players (organizations). The fundamental role of these rules, and the cornerstone of their credibility/enforceability, is to reduce the complexity of the world in which the game is played by reducing both the scope of possible choices and the degree of uncertainty associated with that scope.

Very generally speaking, a market emerges because it is 'framed' by and 'based on' rules (formal or informal, legal or cultural) which limit the field of action as well as the modalities of the player's actions by making the agent's behavior moderately predictable, the development of impersonal trade possible and the division of labor profitable (North 2005). In this respect, North's theory (new-institutional economics) is not very far removed from the conclusions of economic sociology (Granovetter 1985; Callon et al 2007; Le Velly 2012).

Echoing Arthur, North (1990) considers that both institutions and technologies, are characterized by increasing returns to adoption and the same self-reinforcing mechanisms including large start-up and fixed costs, learning effects, coordination effects and adaptive expectations (Donnelly, 2009). Institutions would therefore behave in a pretty similar way to complex technologies, with no guarantee that the rules adopted by a society are the fairest (in terms of social justice) or the most efficient (in terms of economic development); moreover, once established, institutions are difficult to modify or substitute.

North goes beyond these path-dependence similarities by extending Arthur's original concept, in particular introducing elements of Transaction Cost Theory (TCT) such as opportunistic behavior, limited rationality of economical agents, weak enforceability and positive transaction costs ${ }^{7}$.

First, institutions are the product of social interactions between groups (organizations) who compete with each other in order to defend their particular interests through an opportunistic approach. Consequently, there is no guarantee that a given society develops and selects rules that allow it to maximize social well-being rather than the economic benefits of a particular group.

Second, while it is true that institutions can be modified continuously over time, North points out that institutional changes can only be incremental and bounded due to the limited rationality of economic agents.

Third, for rules to be efficient, they need to be accompanied by effective enforcement mechanisms. In the absence of these mechanisms, good rules can produce bad games or bad choices, just as bad rules would.

Finally, there is no guarantee that 'sub-optimal' rules will be superseded in the long-run by better rules (as argued by Alchian 1950; Alchian and Demsetz 1973; North and Thomas 1973). The shift towards more desirable rules for players will come to a halt when it appears too costly from a transactional point of view. With regard to this, it is clear that North (1990) combines Arthur's speculations with the 'Coase theorem' (Coase 1960). He concludes that, in the presence of increasing adoption returns, i.e. the increased probability of preferring a given institutional framework because it was previously preferred by others, and positive transaction costs, which reflect incomplete and uncertain markets, the selected institutions ultimately become incontestable, greatly influencing society's present and future economic returns. This is the socalled 'institutional path dependence' effect and 'lock-in' situation.

\footnotetext{
${ }^{7}$ Highlighted by Coase in his pioneering work on the "nature of the firm" (Coase 1937), transaction costs ("costs of discovering the appropriate price") became the key to a theoretical approach in its own right (Williamson 1975, 1985, 1991).
} 
The path dependence literature, both evolutionist and institutionalist, has naturally been subject to criticism, notably with regard to what can legitimately be defined as a lock-in dependent situation. Most critics consider that Arthur's path dependence concept has been stretched considerably, becoming the unduly dominant explanation of institutional change. While Liebowitz and Margolis (1990, 1995, 2012) strongly criticize David's works, arguing that lockin situations are not as frequent as 'new positive feed-back' economists claim, Williamson (1993) - who introduced the remediability principle as an equivalent to the efficiency principle - limited the number of lock-in situations to those that are 'irremediable'. In the same vein, Rixen and Viola (2015) point out that North contributes to this concept-stretching by claiming that limited incremental changes in institutions occurring in a path-dependent situation may lead to continually different outcomes, thus weakening Arthur's initial concept predicting a unique outcome once the path is taken.

These criticisms, of course, reduce the scope of the path dependence analysis, but also help discriminate situations that can legitimately be analyzed in this manner. As North (1990, p. 98) himself states, "Path dependence is a way to narrow conceptually the choice set and link decision-making through time. It is not a story of inevitability in which the past neatly predicts the future".

\section{2) Institutional path dependence in international trade}

Echoing North (1990), but without discussing the variables that explain increasing returns to adoption, we suggest that the international market, and in particular that of fresh agricultural products, is governed by institutional devices (international institutions) that are not always capable of negotiating optimal rules or of quickly renegotiating existing rules when better solutions are available. This situation, that we can qualify as 'institutional lock-in', would be exacerbated by the presence of significant transaction costs linked to negotiation and renegotiation activities and generated by (i) the slowness of the production process for international standards, (ii) the limited universality of international standards and (iii) their low level of enforceability.

With regard to the first point, a simple glance at the number of voters and the voting procedure used by the main international trade organization (unanimous vote, WTO) is sufficient to explain the long decision-making times. In the case of the IPPO (International Plant Protection Organization) for example, the average time required to develop an ISPM (International Standard for Phytosanitary Measures) is about 10 years. The slowness of the standards production process results from the extensive negotiations necessary to agree on common rules. It is also a sign of the existence of high transaction costs specific to the voting method adopted. This does not mean, however, that transaction costs (related to bilateral negotiations) would be lower in the absence of international institutions. Quite the contrary. We simply mean that international institutions do not have the capacity to make these costs disappear, despite emerging in order to reduce the transaction costs associated with negotiating common standards (Keohane 1982).

In the case of global trade in fresh agricultural produce, the difficulty in producing a universal international rule results from the local nature of the phytosanitary problems observed. Despite the universalist vocation of international trade institutions ${ }^{8}$, global trade in this type of product is strongly influenced by the existence of variable geographical phytosanitary risks, i.e. specific

\footnotetext{
${ }^{8}$ See article 1 of the Marrakesh agreement (1994), the foreword to the SPS agreements (1995) or the text of the ISPM 28 standard: "The purpose of harmonizing phytosanitary treatments is to support efficient phytosanitary measures in a wide range of circumstances and to enhance the mutual recognition of treatment efficacy by NPPOs, which may also facilitate trade".
} 
to the geo-climatic origins of the exporter/importer pairs and the product/quarantine organism pairs. The heterogeneity of the situations prevents the emergence of universal standards (Castonguay 2005) and confines international institutions to the production of 'general rules'. In this respect, the two main international agreements on sanitary risk management in plants (SPS agreement, IPPC) grant each member country the right to set the phytosanitary standards it deems most appropriate ${ }^{9}$, thus facilitating the expression of countries' particular interests in bilateral negotiations and generating even higher transaction costs.

With regard to the weak enforceability of international standards as a source of further transaction costs, two scales of analysis can be used: the first international and the second bilateral.

In the first case, an international market is considered to be a trading area essentially governed by common rules and international organizations (this is the image we have of the WTO and the DSB, for example). At this level, the literature tries to establish whether or not international control bodies have the necessary authority to enforce (as a last resort) the standards stipulated in international agreements. Vidigal (2017) points out that, despite their slowness, multilateral dispute settlement systems have been used more extensively than bilateral adjudications (under the FTA), because of the 'multilateral enforcement pressure that is integral to WTO adjudication'. Contrary to this, Berkowitz et al. (2004) believe that multilateral dispute settlement systems would be too slow and lack power. This would explain the importance of national authorities, the tendency for private commercial agents to include clauses in their commercial contracts specifying which national jurisdiction applies, the tangible methods for dispute settlement and the relevant international court of arbitration (Casella 1996), as well as the persistence over time of many outstanding international commercial disputes.

When international trade is considered to be simply the sum of bilateral relations, it is the 'border effect' - understood here to be the gap between national jurisdictions (Turrini and Ypersele 2002), their quality (Rodrik et al. 2004) and their legal guarantees (Anderson and Marcoullier 2002) - which would be the most immediate cause of weak enforceability of contracts and therefore of reduced trade. As we recalled in the previous paragraph, the nature of quarantine problems is such that standards are, more often than not, set unilaterally or bilaterally. This leads to disputes which could not only be more numerous but also less easy to resolve, given the absence of any multilateral pressure.

Finally, all these elements (the slowness of the public standards production system as well as their low level of universality and enforceability) indicate not only the presence of high transaction costs linked to the negotiation of standards, but also the lack of a guarantee that regulations will emerge or persist solely because of their efficiency in optimizing trade costs (David and Zeitlin 1998).

Based on these avenues of reflection, we focus on two aspects of the so-called 'cold treatment' standard. On the one hand, we show that, in the absence of a common international standard, the definition of the practice of 'cold treatment' falls to the individual countries and that among the possible definitions, the American one has become the international reference. On the other hand, we illustrate that 'cold treatment' (according to the US definition) is almost systematically carried out 'in transit', not only for practical reasons but also because this inspires greater confidence in the importing country, while there is also a lack of alternatives. In accordance with the neo-institutional theoretical framework employed, we suggest that the absence of alternatives cannot be explained by specific economic or technical disadvantages,

\footnotetext{
${ }^{9}$ On condition that the restrictions adopted are scientifically justified and that they are not discriminatory (Art. 2 and 3 of the SPS agreement, 1995).
} 
but rather by the existence of an 'institutional path dependence' situation that prevents their emergence - in other words a situation in which the cost of maladjustment (Williamson 1985) generated by existing rules is exceeded by the cost of their renegotiation.

\section{2) 'Cold treatment': history of a path-dependent device}

As mentioned above, in 'path dependence' literature 'technical or institutional lock-in' situations emerge when several conditions are observed. These include the existence of competing alternative techniques or standards; the possibility, under the assumption of increasing adoption returns (Arthur 1984; David 1985), of identifying the "accidents of history", meaning random accidents along the way that allowed one of the existing devices (technical or standard) to emerge at the expense of others; and transaction costs (North, 1990) that are sufficiently high that it no longer seems viable to leave the chosen path, despite the existence of more effective alternatives.

The case of 'cold treatment', particularly in-transit, would not appear to be an exception to this rule. In this section, we try to describe all the conditions that have made the USDA-APHIS T107-a standard a 'de facto' international reference, i.e. because of its ability to achieve a consensus among market operators and be adopted by a significant number of countries outside the United States.

\section{1) The 'cold treatment' standards market}

At present, no international 'cold treatment standard' has been developed at a multilateral level. The reasons for this were presented in the previous section. First heterogeneity of the geoclimatic and phytosanitary conditions underpinning the international trade of fresh produce prevents the emergence of such a universal standard. Second, the WTO and IPPC both recognize that each member has the right to define their own SPS protection system (SPS Agreement, 1995), which is most often done unilaterally or bilaterally. Consequently, the only institutional scale at which cold treatment standards can possibly be developed is the national level, and only then through bilateral trade protocols.

At this level, we realize that different versions of the so-called 'cold treatment standard' coexist for a single product. These versions differ in scope and compete with each other in terms of their ability to attract/retain users, thereby guaranteeing the potentially competitive nature of the market. For example, while in Jordan cold treatment is to be carried out exclusively 'in transit' for a period of 40 days at a temperature of $1^{\circ} \mathrm{C}$, Sri Lanka offers a choice between cold treatment before shipping or in transit and between 4 different temperature/time frame pairs (Tab.1, infra).

\section{2) The emergence of 'USDA-APHIS in-transit cold treatment': an American history}

Despite the variety of operational definitions that we have highlighted above and the right of each country to define its own standard, careful examination of cold treatment standards currently imposed by importing countries on a panel of leading apple exporting countries (Tab.1) leads us to qualify the USDA-APHIS standard (and in particular the T107-a protocol ${ }^{10}$ ) as predominant. As such, it is relatively common for countries outside the United States to require French, South African or Australian exporters, for example, to comply with the US cold

\footnotetext{
${ }^{10}$ This standard specifies not only the temperature/days pairings for the cold treatment of Mediterranean fruit fly in a wide range of fruits (deciduous, stone and citrus fruits among others), but also all the details concerning the number of heat sensors and the positioning conditions (atmospheric or in the pulp of the fruit) in the refrigerated units or the containers. Document available at: https://www.aphis.usda.gov/aphis/ourfocus/planthealth/completelist-of-electronic-manuals.
} 
treatment standard or with conditions very similar to it ${ }^{11}$. In the case of France, 5 out of 15 destinations requiring specific phytosanitary treatments for the control of Ceratitis Capitata demand compliance with the USDA-APHIS T107-a standard while for South-Africa, 4 of 12 listed destinations require the USDA-APHIS standard, with the same proportion (one-third) observed in the Australian case. In light of the limited data available for Italy with regard to the apple/Mediterranean fruit fly pair (only one bilateral protocol signed, namely with the USA), we focus on a similar product: kiwis. The result is very similar as USDA-APHIS 107-a still appears to be predominant, especially if we limit our study to Asian countries only.

Table 1: here

In accordance with the theoretical framework used above and the assumption of increasing adoption returns, we explain the current predominant position of the USDA/APHIS standard compared to other international standards by the 'historical accidents' that gave it an initial advantage.

The appearance of Ceratitis Capitata in Perth (Australia) in 1895 (Bonizzoni et al. 2004), followed by the infestation of Hawaii in 1907 due to its trade relations with Australia (Vargas et al. 2001) as well as the crises in Florida in 1929, Texas in 1966 and finally in California in $1975^{12}$ are, in our opinion, the 'accidents of history' that drove the US to become the first country - from the end of the $19^{\text {th }}$ century onwards - to experiment with and use cold air as a preventive phytosanitary measure against the Mediterranean fly in the context of a burgeoning fresh fruit trade (Wilcox and Hunn 1914).

In a document published in 1952, Richardson noted that in response to the waves of Mediterranean fly contamination mentioned above, the "first large-scale commercial use of 'cold treatment' (in cold-storage) was observed in Florida in 1928". The first 'in-transit cold treatment' protocol was subsequently approved in 1937 for products arriving in New York (notably grapes). The note written by Richardson is all the more pertinent because it already specified the conditions for validating 'in-transit cold treatment': the use of atmospheric and fruit-pulp sensors to ensure compliance with the treatment time and temperature instructions, as well as details on the number of probes required per compartment ${ }^{13}$.

The repeated Mediterranean fly contamination crises in the United States during the $20^{\text {th }}$ century pushed the American authorities to develop different methods of controlling Ceratitis Capitata at an early stage and to make 'cold treatment' both a tool for domestic management of quarantine risks (with regard to products imported from contaminated territories or countries) and a way to reach pest-free markets. With regard to this second point, it is important to understand the link with the United States' position in the $20^{\text {th }}$ century international apple trade. Unlike in Europe (France and Italy), North American exports have always been geographically diversified and oriented towards countries with stringent phytosanitary constraints. The figure

\footnotetext{
11 Source France: https://teleprocedures.franceagrimer.fr/Expadon/Login/Login.aspx?ReturnUrl=\%2fexpadon. Source Italy: https://www.politicheagricole.it/. Source South Africa: https://ppecb.com/documents/. Source Australia: http://www.agriculture.gov.au/export/micor.

${ }^{12}$ URL: http://entnemdept.ufl.edu/creatures/fruit/mediterranean_fruit_fly.htm\#top.

${ }^{13}$ Richardson (1952) says: "usually each compartment has at least four elements, two to measure the air temperature and two for the fruit". It is interesting to observe that number of sensors per container remains 4 to this day: 1 atmospheric and 3 in the fruit pulp.
} 
below (Fig. 1) shows that while $40 \%$ of American apple exports were shipped to Asian countries (susceptible to Mediterranean fruit fly) during the $1980 \mathrm{~s}^{14}, 90 \%$ of French apple exports were shipped to northern European countries (primarily concerned by health quality issues: MRL).

It can therefore be assumed that the United States was very quickly required to negotiate bilateral protocols incorporating 'cold treatment' and therefore to have its expertise in this field recognized, long before the more recent arrival of European products.

\section{Figure 1: here}

\section{3) Increasing adoption returns: when the USDA/APHIS standard became the 'system'}

While the prior presence of American apples in countries with stringent phytosanitary constraints makes it possible to explain the initial advantage acquired by the USDA/APHIS standard since the middle of the $20^{\text {th }}$ century, more recent additional elements suggest a selfreinforcing effect of the standard, an effect that the literature explains by the presence of increasing returns to adoption (Arthur 1984; David 1985; North 1990). Here, we provide some examples involving micro to macro scales.

The USDA-APHIS certifies incoming vessels and containers, as well as the recording equipment (thermal probes) used to certify 'in-transit cold treatment' (CPHST database ${ }^{15}$ ). The aim for the American phytosanitary authority is above all to ensure that imports comply with the conditions described by the national cold treatment standard. Although this certification is in theory an instrument for controlling only incoming flows (imports), we suggest that approved vessels, containers or other technical facilities function as vectors for the spread of the USDAAPHIS standard throughout the world. For example, since 2018, the ocean carrier company APL has ensured all its trading partners (not only the US) that its 'in-transit cold treatment' operations (SMARTcool $®$ ) are carried out in USDA-APHIS-certified containers, regardless of the final destination ${ }^{16}$. Such a guarantee can be analyzed both as a means for APL to break even on initial USDA-standard adoption costs (start-up costs), and as proof of the existence of 'the coordination effect' between the American standard and international private agents' investments.

Another example of coordination effects can be seen in the fact that several international companies manufacturing thermal probes (such as Comark, Carrier or Senmatic) promote their USDA-compatible probes, simply calling them 'USDA probes'. It is not beyond the realms of belief that these companies use USDA-APHIS accreditation to increase their international credibility while at the same time promoting the adoption of the USDA-APHIS standard.

In a similar way, we point out the recent emergence of insurance systems or 'remote control' systems for 'in-transit cold treatment' proposed by the main international shipping companies ${ }^{17}$. While these systems may, on the one hand, increase confidence in the reliability of cold

\footnotetext{
${ }^{14}$ Unfortunately, the FAO and Comtrade trade data do not go further back in time.

${ }^{15}$ URL: https://vessels.cphst.org/index.cfm?

${ }^{16}$ Source: https://www.apl.com/our-offerings/refrigerated-cargo/smartreefers/cold-treatment.

${ }^{17}$ This is the case of the "Cold Treatment Guarantee" proposed by the company CMA-CGM, the "Cold Treatment Assured" guarantee proposed by the company APL, the "Cold Treatment" service proposed by COSCO (https://worldmaritimenews.com/archives/132727/coscon-keeps-it-cool/) and the remote container management service (RCM) proposed by MAERSK, to name but a few examples.
} 
treatment operations carried out in transit, they can also be seen as a specific investment choice made by shipping companies as a consequence of the growing importance of this particular practice for the international trade of fresh produce.

The impact of the USDA-APHIS standard on international relationships can also be assessed at the institutional level. Bilateral trade protocols recently signed by Italy, South Africa or Australia, for example, with Asian countries (China, Thailand, India, Indonesia or Iran among others) explicitly state that cold treatment must be carried out 'in-transit' and exclusively in USDA-APHIS-approved vessels or containers or using USDA-APHIS-certified probes. This is an additional step beyond simply requiring the respect of temperature/day pairings.

One final example is that in April 2018, after several years of consultation, the IPPO approved the ISPM 42 on 'requirements for the use of temperature treatments as a phytosanitary measure'. This international standard specifies certain requirements to ensure that cold treatment is successful. We learn that 'cold treatment' begins when the required temperature is reached 'at the heart of the fruit', that this temperature can only be recorded by thermal sensors placed 'at the heart of the fruit' and that the minimum number of fruit-pulp sensors to be used is three. While this international standard does not provide a complete definition of how cold treatment is supposed to be achieved, it does specify how the temperature is to be measured. With the emergence of this new IPPO standard, we can point out that the ISPM 42 is a relatively faithful reproduction of the current USDA-APHIS standard ${ }^{18}$ and is very similar to the "cold treatment' protocol introduced in the USA 80 years earlier as described by Richardson (1952).

\section{3) 'Lock-in situation' and disposal costs: a case study of French apple exporters}

In the previous section, we documented evidence illustrating how the USDA-APHIS T107-a standard is predominant in the international apple trade and deduced what might have been the historical causes underpinning this. In this section, we examine a particular case-study - that of French apple exports - to show how expensive it is to avoid the practice of 'cold treatment' as established by the American standard, despite the existence of an alternative practice which is potentially both more effective and less expensive.

3.1) The French apple export sector: a sector in the process of restructuring, sensitive to phytosanitary constraints

While French fresh apple exports have been moderately constant since the 1960s, their relative market share (in relation to production) has increased significantly and the number of destinations has expanded significantly. In the 1980s, French exports accounted for about $20 \%$ of domestic production and for one-third in 2015 (Faostat). At the end of the 1990s, European countries, and in particular those in the North, absorbed almost all French apple exports (93\%). More recently (2013), the same region absorbed only $73 \%$ of exports with the remainder now shipped to North Africa (for the most part Algeria) and the Middle East (Saudi Arabia and the United Arab Emirates).

\footnotetext{
${ }^{18}$ For example, we reproduce here some passages supporting our claims, drawn from the USDA-APHIS Treatment Manual and ISMP 42 (CIPV). USDA-APHIS Manual: "Fruit intended for in-transit cold treatment must be precooled to the temperature at which the fruit will be treated prior to beginning treatment". ISMP 42: "Prior to beginning treatment, the commodity may be precooled to the temperature at which the commodity will be treated"; USDA APHIS Manual: "The number and location of temperature sensors is based on the cubic capacity of the compartment ... The minimum requirement is three sensors"; ISMP 42: "The number of sensors required to monitor the temperature of the commodity also depends on the temperature mapping and the size of the treatment facility ... in the temperature treatment facility, at least three sensors should be used".
} 
In this context of significant change, it must be noted that the Asia and Americas region, which are dynamic in terms of consumption, remained marginal destinations for French exports $(<1 \%$ of fresh apples exported in 2013), although this figure increased in $2015^{19}$.

Recent works (DeMaria et al. 2018) have highlighted that import bans and phytosanitary restrictions imposed by importing Asian countries help to explain the limited trade in this area. It should be noted that the risk of contamination by Ceratitis Capitata is the most frequently cited risk and that 'cold treatment' is systematically required by these countries: of the 15 countries requiring special treatments on apples originating in France, $14^{20}$ require a specific "cold treatment" for Mediterranean fruit fly (Exp@don database). It is therefore clear that the risk of contamination by Ceratitis Capitata is a major problem for French operators, and that 'cold treatment' is the main solution they are systematically forced to adopt.

According to information collected from French apple sector operators (ANPP, Interfel, Aneefel, cooperatives ${ }^{21}$ ), almost all apples exported to countries requiring cold treatment receive 'in-transit cold treatment' in refrigerated containers equipped with thermal sensors. Still based on the information provided by these operators, the cost of this operation varies (depending on the shipping company employed), but is about $€ 1,100 /$ container.

This extra cost, equivalent on average to $5 \%$ of the value of the exported goods, reduces the overall competitiveness of the exporting sector, causing the industry (ANEFEL, INTERFEL, ANPP) to claim ${ }^{22}$ that the current practice of 'cold storage' would be equivalent to "cold treatment" in terms of its ability to limit the risk of contamination by Ceratitis Capitata, as "cold storage' is generally carried out at temperatures compatible with those required by the main cold treatment protocols (between $0^{\circ}$ and $2.5^{\circ} \mathrm{C}$ ) and for a much longer period of time (from one to several months). Proof of the reliability of 'cold storage' as a phytosanitary risk management tool is provided by the Franco-Chinese protocol, the oldest bilateral protocol signed by France (in 2000). This protocol specifies the temperature/day pair to be respected, but does not demand the use of fruit-core probes or in-transit treatment.

\section{2) 'In-transit cold treatment' vs. 'cold storage before shipping': technical, economic and transactional differences}

In addition to historical accidents, the predominant position of 'in-transit cold treatment' in the international trade of fresh fruit can also be explained by a number of advantages. Perhaps the most striking of these is that two operations (transport and treatment) can be carried out at the same time. This time-saving factor overshadows two other advantages: first, the fact that the treatment is carried out on the open sea limits any form of ex-post contamination of the fruit; and second, adopting a just-in-time approach makes it possible to react as effectively as possible to market prices, particularly at the beginning of the season, whereas cold-storage before shipping (in warehouses) would delay the departure of the vessel by several weeks, potentially affecting the exporters' scope for bargaining.

However, apart from this short delay which makes in-transit cold treatment of freshly harvested fruit a major asset for negotiating better-selling prices, 'cold storage before shipping' has equally attractive advantages for fruit that can be kept cold for a long time (this is the case for apples but not strawberries, for example). Technical advantages include the fact that a coldstorage warehouse is designed to generate cold, whereas a refrigerated container can only

\footnotetext{
${ }^{19}$ In 2015, more than 9 thousand tons were exported to Asia and more than 5 thousand tones to Latin America (Source: Business France based on Comtrade data from 2015).

${ }^{20}$ Unilaterally (Algeria, Bangladesh, India, Iran, Jordan, Nigeria, Myanmar, Sri-Lanka) or bilaterally (China, US, Morocco, Taiwan, Thailand, Vietnam). Israel is the only country not to systematically impose cold treatment.

${ }^{21}$ Information collected as part of the ANR Sustain'Apple project (2014-2018).

${ }^{22}$ In particular, within the framework possible amendments to the bilateral trade agreement with Thailand.
} 
maintain a given temperature (Foulquier 2007). In a cold-storage warehouse, it is therefore not only possible to reach the temperature imposed by bilateral protocols (as precooling is already performed there), but also to maintain it for several months, if necessary; this is impossible in a container. Furthermore, 'insect-proof' certified cold storage and packaging stations reduce the risk of re-contamination, similar to the isolation conditions of a shipping container.

The financial benefits of cold storage are also significant. First, 'cold storage before shipping' not only saves the extra cost of 'in-transit cold treatment' but, since most French cold rooms usually operate at temperatures compatible with those required by importing countries (between 0.5 and $2.5^{\circ} \mathrm{C}$ ), no additional operating costs would be incurred. Secondly, as 'cold storage before shipping' is centralized and constantly controllable, it allows the exporter to react quickly in the event of a treatment failure. In this respect, while a treatment failure implies a loss of time (the need to start the treatment protocol again from scratch, which is possible in a cold storage center), it does not require the destruction of the goods or their redirection to a less profitable market (which usually happens with in-transit cold treatment failures since containers are not designed to generate cold). Finally, as a larger volume of apples can be processed in a cold room than in a container, economies of scale and organizational economies can be enjoyed. To illustrate this, let us take the example of inspections. In the case of in-transit cold treatment, each container is subject to a pre-departure inspection by a national phytosanitary authority which certifies the correct launch of the cold treatment protocol. In the case of 'cold storage before shipping', it is the cold room (which is equivalent to several containers) that is inspected in order to certify the end of the treatment.

While it is reasonable to think that 'cold storage before shipping' has undeniable advantages, the experience of international trade tells a different story, and this can be traced back to the differing nature of the two practices. It should be recalled that 'cold treatment', as defined by the USDA-APHIS standard, entails both an obligation of result and of means. It involves an obligation of result because all importing countries requiring France to apply 'cold treatment' implement inspections on arrival (source: Exp@don France-AgriMer), while it entails an obligation of means because, as we have seen above, 'cold treatment' implies compliance with three conditions: a given 'fruit-core' temperature, a precise duration and the use of specific recording instruments. It is with regard to this last point - thermal probes - along with transactional constraints that the difference between cold storage and cold treatment emerges.

A cold storage room is generally designed to generate cold and to maintain so-called 'commercially cold' temperatures (between 0.5 and $2.5^{\circ} \mathrm{C}$ ). This can be qualified as a generic asset insofar as there is no specific equipment to carry out particular operations: in other words, it is designed in such a way as to maintain a precise environmental temperature within the room as a whole and not only at particular points in the room. In contrast, 'cold treatment' as commonly practiced requires dedicated cold rooms ${ }^{23}$, i.e. with specific equipment as described by Transaction Costs Theory (Williamson 1985). This specific equipment comprises mobile thermal probes and, more precisely, probes used to record the evolution of the 'fruit-core' temperature.

\footnotetext{
23 'Dedicated' in the sense of perfectly airtight, fitted with a sufficiently precise temperature recording system operating non-stop, equipped with recording sensors and operated by staff trained in the calibration and positioning of sensors requiring an 'insect-proof' environment. Dedicated assets also in the sense of 'immobilized' for any other use: once the apples are stored, the cold rooms must be sealed for the duration of the treatment. With this in mind, it is enough to browse the USDA-APHIS manual to note the number of technical constraints that must be complied with in order to perform cold treatment operations in a cold room, for example the number of sensors ranging from 3 to 14 depending on the number of pallets stored in the room (USDA-APHIS Treatment Manual, chapter 6-4-1, Certification of cold treatment).
} 


\section{3) Non-market constraints}

\section{The 'scientific evidence approach' and its limitations}

There are two ways of dealing with this issue. The first would be to make the necessary investment to transform conventional cold rooms into dedicated cold rooms (e. g. in accordance with USDA-APHIS guidelines). This investment is costly and profitable only for the practice of cold treatment (hence the notion of specific asset borrowed from Transaction Costs Theory). This solution would also represent a further step toward the dominance of American practice. The second approach would be to provide proof that, under certain conditions, 'cold storage' in a conventional cold room can achieve the same results as 'cold treatment'. The issue here is to 'produce sufficient scientific evidence" ${ }^{24}$ that would legitimize this claim and to this end, it is necessary to request and obtain a status of 'technical equivalence', change ISPM 42 and possibly amend the bilateral trade protocols.

This 'scientific evidence approach', nevertheless displays two major limitations.

The first relates to the origin of the scientific evidence: each importing country involved in a negotiation would be entitled to demand that the exporting country produce its own scientific results in the field. In practice, evidence cannot be borrowed from other countries that have already carried out tests ${ }^{25}$ and each exporting country would therefore have to carry out the test the underlying reason for this is the heterogeneity of the geo-climatic, physical and/or varietal conditions in which the tests are carried out. This could potentially result in the production of scientific evidence becoming redundant and very costly.

Laboratory experiments recently conducted in France by the CTIFL (Vincent MathieuHurtiger, forthcoming) meet this requirement of originality of proof. The CTIFL has tested the hypothesis that precooled apples stored at a temperature equal to or lower than $2.22^{\circ} \mathrm{C}$ in French conventional cold rooms for a period of at least 18 days (in accordance with the USDA-APHIS standard), do not show any trace of Ceratitis Capitata (regardless of the QO's development stage).

The second limitation concerns the specifications of the experimental protocol. To clarify this point, it should be recalled that Japan, as well as New Zealand and Australia, require exporting countries to test quarantine organisms on a minimum number of specimens (30 thousand for the Mediterranean fly) to achieve probity thresholds of 9 (Sproul 1976; Follett and Hennessey 2007). In the same vein, it should be recalled that, in 2002, the USDA-APHIS tightened the T107-a cold treatment program, following observation of the low probity of the temperature/day pairs previously requested (USDA-APHIS 2002).

All these unilateral constraints relating to the means of producing scientific evidence have the potential effect of multiplying the cost of producing such evidence by the number of countries with which negotiations would be undertaken.

\footnotetext{
${ }^{24}$ In accordance with the SPS agreement (Art 2, para. 2).

${ }^{25}$ In this respect, let us recall the negotiations between Chile and Japan with regard to cold treatment of Mediterranean fruit fly. During the 1980s, Japan demanded that it participate (physical presence in Chile) in defining the experimental protocol and the experimentations aimed at demonstrating the effectiveness of cold treatment in managing Mediterranean fruit fly. The experimentations lasted between two and three years (mid1980s). Once the effectiveness of the treatment was acknowledged, exports could begin. Unlike other Asian countries (China, Taiwan, Thailand), Japan was not satisfied by the scientific proof initially provided by Chile, despite the fact that this same proof had been validated during similar negotiations with the US. It demanded a bilateral test procedure before validating the process (information collected in 2016 by J.M. Codron during an interview with Roberto Mir of the Servicio Agricola y Ganadero, SAG-Chile).
} 
However, a breakthrough was made in 2016 when the Technical Panel on Phytosanitary Treatment (TPPT) concluded on "the absence of scientific evidence supporting the idea that populations of Ceratitis Capitata, originating from remote geographical regions, would react differently to cold" ${ }^{26}$. The TPPT qualifies this conclusion as a major step forward in the process of harmonizing 'cold treatment' techniques. Despite this, no ISPMs have since been produced on this subject by the IPPC, and no country seems to have used this argument in recent negotiations.

\section{The 'negotiation approach' and its limits}

Despite the technical and economic advantages that can be associated with the use of 'cold storage' as an alternative technique for managing the risk of contamination by Ceratitis, and the emergence of scientific studies conducted to demonstrate the effectiveness of controlled cold storage, international recognition of this alternative is not on the agenda. In our opinion, the explanation lies in the nature of the institutional structures governing the international market for fresh agricultural products, and it immaterial whether we analyze the international market by adopting an international or bilateral perspective.

In the first case, the institutional itinerary that must be followed for a risk management technique to be recognized as equivalent to an existing one is potentially long. It is carried out through the technical equivalence and/or harmonization commissions of internationally recognized bodies: in the case of plant products, this is in the IPPC, and in particular the Technical Panel on Phytosanitary Treatment (TPPT), where discussions take place in working groups which have only an advisory value based on the technical/scientific elements provided by interested parties. Apart from the length of the procedure and the purely consultative nature of the work of these panels however, the positive effect of international recognition of technical equivalence does not ensure that the new technique will certainly be taken into account by both old and new trading partners.

This brings us back to our second scenario: the route through bilateral negotiations. This is an obligatory step which is long (10 years on average ${ }^{27}$ ), which must be reiterated for each country and which involves several entities including trade operators (who are pressing for the opening of new countries), diplomatic networks (who represent a country's political and commercial interests), networks of experts (who participate in country risk analysis) as well as ministerial representatives who proceed with the ratification of agreements and protocols. The institutional transaction cost of setting up and operating such a system is therefore far from negligible.

\section{4) Conclusions}

In an increasingly globalized world in which goods, services and people move across national borders at an ever increasing pace, the WTO, through the SPS Agreement (1995), recognizes that each of its "Members [has] the right to take the measures necessary for the protection of human, animal or plant life or health" (art 2.1), from trade-induced risks.

In the international trade of fresh agricultural products, one of the most important threats to be considered is that trade may become a vector for quarantine infestations. In accordance with the SPS Agreement, importing countries free from a specific quarantine pest can therefore demand - either unilaterally or through bilaterally negotiated phytosanitary agreements

\footnotetext{
$26 \quad$ Source: $\quad$ https://www.ippc.int/fr/core-activities/standards-setting/expert-drafting-groups/technicalpanels/technical-panel-phytosanitary-treatments/

${ }^{27}$ Duration confirmed by the operators in both the French (France Agrimer) and Italian (Assomela) apple value chains.
} 
(bilateral trade protocols) - that fresh products originating in infested countries be subject to specific phytosanitary restrictions.

For apple exports originating in countries home to the Mediterranean fruit fly, one of the most widely adopted phytosanitary restrictions is cold treatment, in particular because of its quality of thermic treatment (as opposed to chemical or radioactive treatments).

In the case of French apple exports, particularly towards fly-sensitive countries, cold treatment is systematically carried out 'in-transit', i.e. during shipping in specially-equipped containers. This particular treatment method generates an additional cost of around 1,100 euros/container compared to a shipment without treatment.

In this paper, we have tried to understand the reasons underpinning the emergence, success and persistence over time of this specific phytosanitary risk management method, notably in light of its significant cost and the existence of other, cheaper methods of applying cold treatment, in particular the use of 'cold storage' in the cold rooms of fruit stations (in accordance with the Franco-Chinese protocol).

We believe that experiments carried out by the CTIFL on cold storage (Hurtiger, forthcoming) as well as the analysis of some French apple stations show that technical and economic advantages, generally associated with the practice of 'in-transit cold treatment', can equally well be obtained by the alternative and cheaper practice of 'cold storage'. This result does not justify the predominant position of 'in-transit cold treatment' in the international apple trade. To explain the lack of development of alternative practices which are just as beneficial as intransit cold treatment practices from an economic point of view, other arguments of an institutional nature must be called on. By using the theoretical framework of new institutional economics (Section 1), we have determined this specific case to be an example of 'institutional path dependence'. In accordance with the specific literature, we have described the random accidents that led to the emergence of a predominant standard as well as more recent additional elements suggesting a self-reinforcing effect of the standard.

In this respect, as we have seen in Section 2, the practice of 'in-transit cold treatment' emerged in the United States at the beginning of the $20^{\text {th }}$ century in response to a major phytosanitary crisis affecting the domestic fresh fruit trade (Hawaii vs. other federal states). Also in Section 2, we showed that adoption of the USDA-Aphis T107-a standard by many partner countries, particularly in Asia, is not only limited to the adoption of a simple temperature/days correspondence table, but is also reinforced by the development of an imposed set of equipment and human skills certified by the United States Phytosanitary Authority and dedicated to the maintenance of the standard. Such a standard-dedicated device also contributes to pathdependency.

In this context, any attempt to change the predominant standard faces strong institutional limitations generating significant transaction costs.

In light of this, we focused (Section 3) on two major obstacles that exporting countries encounter in an international institutional environment when trying to negotiate (bilaterally or multilaterally) changes in the governance of the fresh agricultural product trade, notably with regards to SPS constraints.

The first obstacle is the slow and cumbersome nature of multilateral negotiations in a field where the heterogeneity of bio-geo-climatic situations inevitably leads to bilateral negotiations. The second obstacle is the need to produce scientific proof, the conformity and quality of which is always subject to the assessment of the importing country. Producing 'tailor-made' scientific proof dedicated to a particular importing country is costly not only in itself, but also because, as we have shown, country-specific knowledge cannot be freely applied to other importing countries, i.e. no benefits from economies of scale. 
These two constraints generate costs which can be described as transaction costs. It is ultimately through these costs that we believe it is possible to explain the persistence of a potentially more costly risk management practice.

In light of the magnitude of these exit costs from path dependence, some exporting countries such as France continue to suffer from the maladaptation costs caused by the need to follow a predominant standard.

\section{References:}

Alchian, A. A. (1950), 'Uncertainty, evolution, and economic theory', Journal of political economy, 58(3), 211-221.

Alchian, A. A., and Demsetz, H. (1973), 'The property right paradigm', The journal of economic history, 33(1), 16-27.

Anderson, J. E., and Marcouiller, D. (2002), 'Insecurity and the pattern of trade: An empirical investigation', Review of Economics and statistics, 84(2), 342-352.

Arthur, W. B. (1984), Increasing returns and path dependence in the economy, University of Michigan Press.

Arthur, W. B. (1989), 'Competing technologies, increasing returns, and lock-in by historical events', The economic journal, 99(394), 116-131.

Arthur, W. B. (1990), 'Positive feedbacks in the economy', Scientific american, 262(2), 92-99.

Beghin, J.C. and Bureau J.-C. (2002), 'Quantitative Policy Analysis of Sanitary, Phytosanitary and Technical Barriers to Trade', International Economics 87: 107-130.

Berkowitz, D., Moenius, J., and Pistor, K. (2004), 'Legal institutions and international trade flows', Mich. J. Int'l L., 26, 163.

Bonizzoni, M., Guglielmino, C. R., Smallridge, C. J., Gomulski, M., Malacrida, A. R., and Gasperi, G. (2004), 'On the origins of medfly invasion and expansion in Australia', Molecular Ecology, 13(12), 3845-3855.

Callon, M., Millo, Y., and Muniesa, F. (2007), Market devices (No. halshs-00177891).

Casella, A. (1996), 'On market integration and the development of institutions: the case of international commercial arbitration', European Economic Review, 40(1), 155-186.

Castonguay, S. (2005), 'Biorégionalisme, commerce agricole et propagation des insectes nuisibles et des maladies végétales: les conventions internationales phytopathologiques, 1878-1929', Ruralia. Sciences sociales et mondes ruraux contemporains, (16/17).

Coase, R. H. (1937), 'The nature of the firm', Economica, 4(16), 386-405.

Coase, R. H. (1960), 'The problem of social cost', in Classic papers in natural resource economics (pp. 87-137), London: Palgrave Macmillan.

David, P. A. (1985), 'Clio and the Economics of QWERTY', The American economic review, 75(2), 332-337.

David, P. A. (1994), 'Why are institutions the 'carriers of history'?: Path dependence and the evolution of conventions, organizations and institutions', Structural change and economic dynamics, 5(2), 205-220.

David, P. A., and Zeitlin, E. (1998), 'Comprendre les aspects économiques de QWERTY: la contrainte de l'histoire', Réseaux, 16(87), 9-21.

DeMaria, F., Lubello, P., and Drogué, S. (2018), 'Measuring the complexity of complying with phytosanitary standard: the case of French and Chilean fresh apples', Bio-based and Applied Economics, 7(1), 39-58.

Disdier, A. C., and Mayer, T. (2007), 'Je t'aime, moi non plus: Bilateral opinions and international trade', European Journal of Political Economy, 23(4), 1140-1159. 
Donnelly, P. (2009), 'Focusing on Process and History - Path Dependence', in J. Hogan, P. Dolan and P. Donnelly (eds), Approaches to Qualitative Research: Theory and Its Practical Application, pp.125-150, Cork: Oak Tree Press.

Dür, A., Baccini, L., and Elsig, M. (2014), 'The design of international trade agreements: Introducing a new dataset', The Review of International Organizations, 9(3), 353-375.

Follett, P. A., and Hennessey, M. K. (2007), 'Confidence limits and sample size for determining nonhost status of fruits and vegetables to tephritid fruit flies as a quarantine measure', Journal of economic entomology, 100(2), 251-257.

Foulquier, E. (2007), 'Le froid, les agrumes et la mer. Logiques de flux, logiques d'espace dans le bassin de la Plata', Géographie, économie, société, 9(3), 315-327

Granovetter, M. (1985), 'Economic action and social structure: The problem of embeddedness', American journal of sociology, 91(3), 481-510.

Hansen, B. A., and Hansen, M. E. (2007), 'The role of path dependence in the development of US bankruptcy law, 1880-1938', Journal of institutional Economics, 3(2), 203-225.

Keohane, R. O. (1982), 'The demand for international regimes', International organization, 36(2), 325-355.

Paul, K. (1994), Peddling Prosperity: Economic Sense and Nonsense in the Age of Diminished Expectations. WW Norton \& Company.

Lavallée, E. (2006), 'Similarité institutionnelle, qualité des institutions et commerce international', Economie internationale, (4), 27-58.

Le Velly, R. (2012), Sociologie du marché, La Découverte, coll. «Repères », 125 p.

Liebowitz, S. J., and Margolis, S. E. (1990), 'The fable of the keys', The Journal of Law and Economics, 33(1), 1-25.

Liebowitz, S. J., and Margolis, S. E. (1995), 'Path dependence, lock-in, and history', Journal of Law, Economics, \& Organization, 205-226.

Liebowitz, S. J., and Margolis, S. E. (2012), 'The troubled path of the lock-in movement', Journal of Competition Law and Economics, 9(1), 125-152.

Ménard, C. (2004), 'The economics of hybrid organizations', Journal of Institutional and Theoretical Economics JITE, 160(3), 345-376.

Marette, S. and Beghin, J. (2010), 'Are Standards Always Protectionist?', Review of International Economics 18(1): 179-192.

North, D.C. (1990), Institutions, Institutional Change and Economic Performance, Cambridge University Press.

North, D. C. (2005), 'Institutions and the process of economic change', Management International, 9(3), 1.

North, D. C., and Thomas, R. P. (1973), The rise of the western world: A new economic history, Cambridge University Press.

OEPP/EPPO (1990), 'Exigences Spécifiques de Quarantaine', Document technique de l'OEPP $n^{\circ} 1008$.

Pierson, P. (2000), 'Increasing returns, path dependence, and the study of politics', American political science review, 94(2), 251-267.

Poelmans, E., and Taylor, J. E. (2019), 'Belgium's historic beer diversity: should we raise a pint to institutions?', Journal of Institutional Economics, 1-19.

Pomeranz, K., and Topik, S. (1999), 'The World that Trade Created: Society', Culture, and the World Economy, 1400, 9-11.

Richardson, H. H. (1952), 'Cold treatment of fruits', Insects: the yearbook of agriculture, 404406.

Rixen, T., and Viola, L. A. (2015), 'Putting path dependence in its place: toward a Taxonomy of institutional change', Journal of Theoretical Politics, 27(2), 301-323. 
Rodrik, D., Subramanian, A., and Trebbi, F. (2004), 'Institutions rule: the primacy of institutions over geography and integration in economic development', Journal of economic growth, $9(2), 131-165$.

Sproul, A. N. (1976), 'Disinfestation of Western Australian Granny Smith apples by cold treatment against the egg and larval stages of the Mediterranean fruit fly (Ceratitis capitata (Wied.))', Australian Journal of Experimental Agriculture, 16(79), 280-285.

Swinnen, J.F.M. and Vandemoortele, T. (2011), 'Trade and the Political Economy of Food Standards', Journal of Agricultural Economics 62(2): 259-280.

Turrini, A., and Van Ypersele, T. (2002), 'Traders, courts and the home bias puzzle', CEPR Discussion Paper No. 3228.

USDA-APHIS. (2002), 'Cold treatment on Fruits', Federal Register, 67(199), 63529-63536.

Vargas, R. I., Peck, S. L., McQuate, G. T., Jackson, C. G., Stark, J. D., and Armstrong, J. W. (2001), 'Potential for areawide integrated management of Mediterranean fruit fly (Diptera: Tephritidae) with a braconid parasitoid and a novel bait spray', Journal of economic Entomology, 94(4), 817-825.

Vidigal, G. (2017), 'Why Is There So Little Litigation under Free Trade Agreements? Retaliation and Adjudication in International Dispute Settlement', Journal of International Economic Law, 20(4), 927-950.

Wilcox, E. V., and Hunn, C. J. (1914), 'Cold storage for tropical fruits', Honolulu (HI): Hawaii Agricultural Experiment Station, University of Hawaii. 12 p. (Press Bulletin; PB-047).

Williamson, O. E. (1975), Markets and hierarchies, New York: Free Press.

Williamson, O. E. (1985), The Economic Institutions of Capitalism, , New York: Free Press.

Williamson, O. E. (1991), 'Comparative economic organization: The analysis of discrete structural alternatives', Administrative science quarterly, 269-296.

Williamson, O. E. (1993), 'Transaction Cost Economics and Organization Theory', Industrial and Corporate Change, 2, 107-56. 